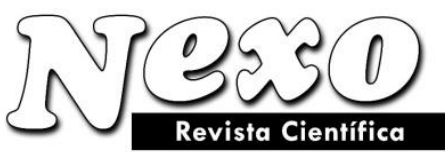

Vol. 33, No. 01, pp. 22-35/Junio 2020

\title{
STUDY OF DYNAMIC REACTION OF TUBULINS IN MICROTUBULES. A QM/MM SIMULATION
}

\section{ESTUDIO DE LA REACCIÓN DINÁMICA DE TUBILINA EN MICROTUBULOS. UNA SIMULACIÓN QM/AM}

\author{
Farnoush Naghsh ${ }^{1}$, Majid Monajjemi ${ }^{2}$, Karim Zare*,1 \\ ${ }^{1}$ Department of Chemistry, Science and Research Branch, Islamic Azad University, Tehran, Iran \\ ${ }^{2}$ Department of Chemical engineering, Central Tehran Branch, Islamic Azad University, Tehran, Iran \\ k-zare@srbiau.ac.ir
}

(recibido/received: 14-octubre-2019; aceptado/accepted: 27-enero-2020)

\begin{abstract}
In this model one-dimensional microtubule is fixed at one of the two and simulated while the opposite end is allowed for growing in random situation. By this study at each step one tubulin has been added to the length for growing microtubule length. Computationally this can be done through generating a uniform random number between $(0,1)$. Microtubules are demonstrated as straight macromolecules consist of the linear chains of tubulin subunits in the length. QM/MM simulation has been applied to study dynamic instability of the microtubule length. It has been calculated a correct dimension around $10^{-6}$ meter of microtubules length consist of around 1650 tubulin dimers. Microtubule growth rate is related to the soluble tubulin dimer concentration and for all results shown here, simulation of any single condition was run 5-10 times.
\end{abstract}

Keywords: Tubulin, Microtubules, Monte Carlo Simulation.

\section{RESUMEN}

En este modelo, los microtúbulos unidimensionales se fijan en uno de los dos y se simulan mientras se permite que el extremo opuesto crezca en una situación aleatoria. En este estudio, en cada paso, se ha agregado una tubulina a la longitud para aumentar la longitud de los microtúbulos. Computacionalmente, esto se puede hacer generando un número aleatorio uniforme entre $(0,1)$. Los microtúbulos se demuestran como macromoléculas rectas que consisten en cadenas lineales de subunidades de tubulina en la longitud. La simulación QM / MM se ha aplicado para estudiar la inestabilidad dinámica de la longitud de los microtúbulos. Se ha calculado una dimensión correcta de alrededor de 10-6 metros de longitud de microtúbulos consiste en alrededor de 1650 dímeros de tubulina. La tasa de crecimiento de los microtúbulos está relacionada con la concentración de dímero de tubulina soluble y para todos los resultados mostrados aquí, la simulación de cualquier condición individual se realizó de 5 a 10 veces.

Palabras clave: Tubulina, Microtúbulos, Simulación Monte Carlo.

Nexo Revista Científica / Vol. 33, No. 01, pp. 22-35 / Junio 2020 


\section{INTRODUCTIÓN}

Since Stathmin is a disordered protein, and their activities are down-regulated by multiple phosphorylations, therefore in complex of the $\mathrm{T}_{2} \mathrm{~S}$ tubulin becomes non-polymerizable (Ringhoff, 2009; Guesdon, 2016).

Since the stathmin is a soluble cytoplasmic protein, is used in regulating rapid microtubule remaking of the cytoskeleton in response to the cell's requirements (Chen, 2015). Since microtubule assemblies determined through the concentration of free tubulins in the cytoplasm, at low concentrations the growth rate at the microtubule ends is languid and results in an increased rate of disassembly (de-polymerization) (Garvalov, 2006).

Recently, especial particles have been discovered inside the microtubules which the particles' existence varied between cell types while the neuronal cells have the most particles (Brouhard, 2014). The stathmin family proteins carry out a major function in regulating rapid microtubule remodeling of the cytoskeleton and also increase microtubule turnover in response to the cell's needs such as extracellular signals (Clément, 2005; Hepler, 2016)

One molecule stathmin interacts with two subunits tubulins " $\alpha \beta$-tubulin" dimers" for building a tight ternary complex (is known as $\mathrm{T}_{2} \mathrm{~S}$ complex) which decrease microtubule destabilizing activity near microtubule polymer (Sahu et al, 2013). One of the important stathmin category proteins is $\mathrm{RB}_{3}$ which shares $(88 \%)$ with other members the stathmin-like domain (SLD) through translated amino-acid identity with that of XB3 (Fig.1) (Akhmanova, 2015; Gupta, 2014)

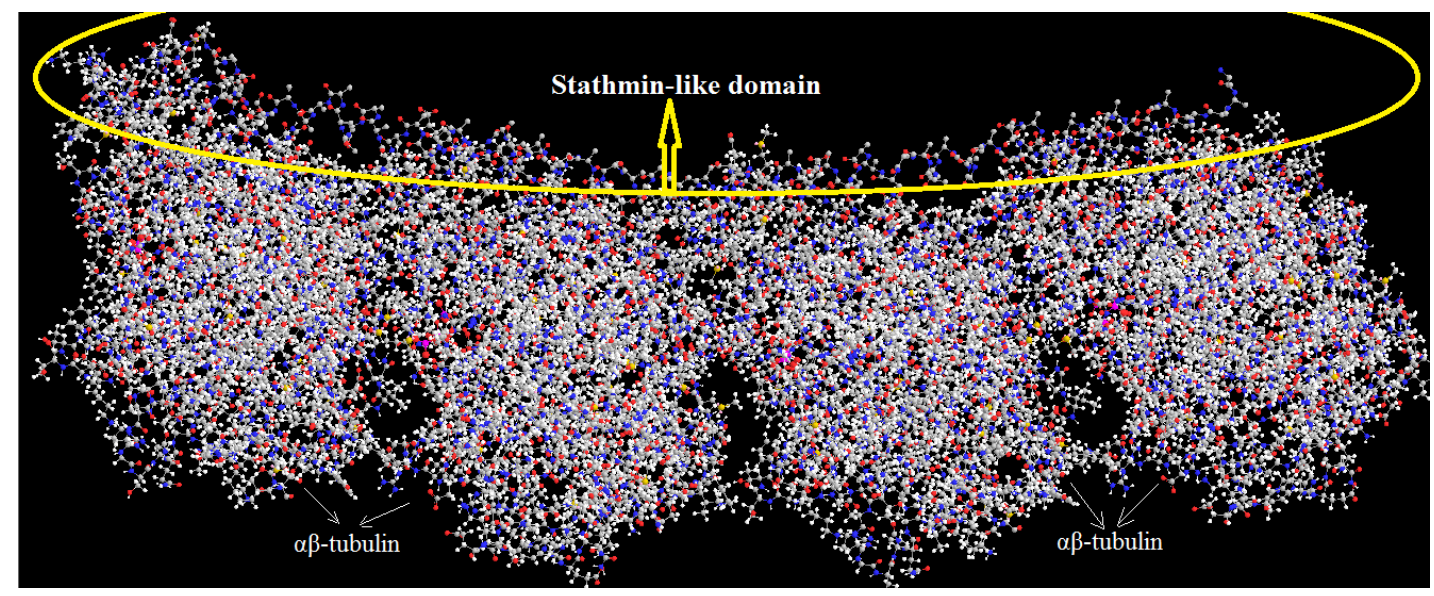

Figure 1. stathmin-like domain (SLD) binding to two $\alpha \beta$-tubulin

In 1984, Burton introduces those particles that could be voided via lumen quickly through reassembly or disassembly of microtubules (Zakharov, 2015).

Proteins that destabilize or destabilized microtubules have been distinguished recently (such as stathmin family proteins and Colchicine) and the protein related to stathmin is expressed in the nervous systems which are known as SCLIP, SCG10, RB3 (and two its splice variants RB3' \& RB3") (Rowlands, 2013)

Via electron microscopy (EM) it can be seen that each proto-filament consists of globular 4nm subunits and it is possible for refined tubulin to assemble with a range of diameters containing between 9 and 16 proto-filaments Fig.2 (Ozon, 1997). 

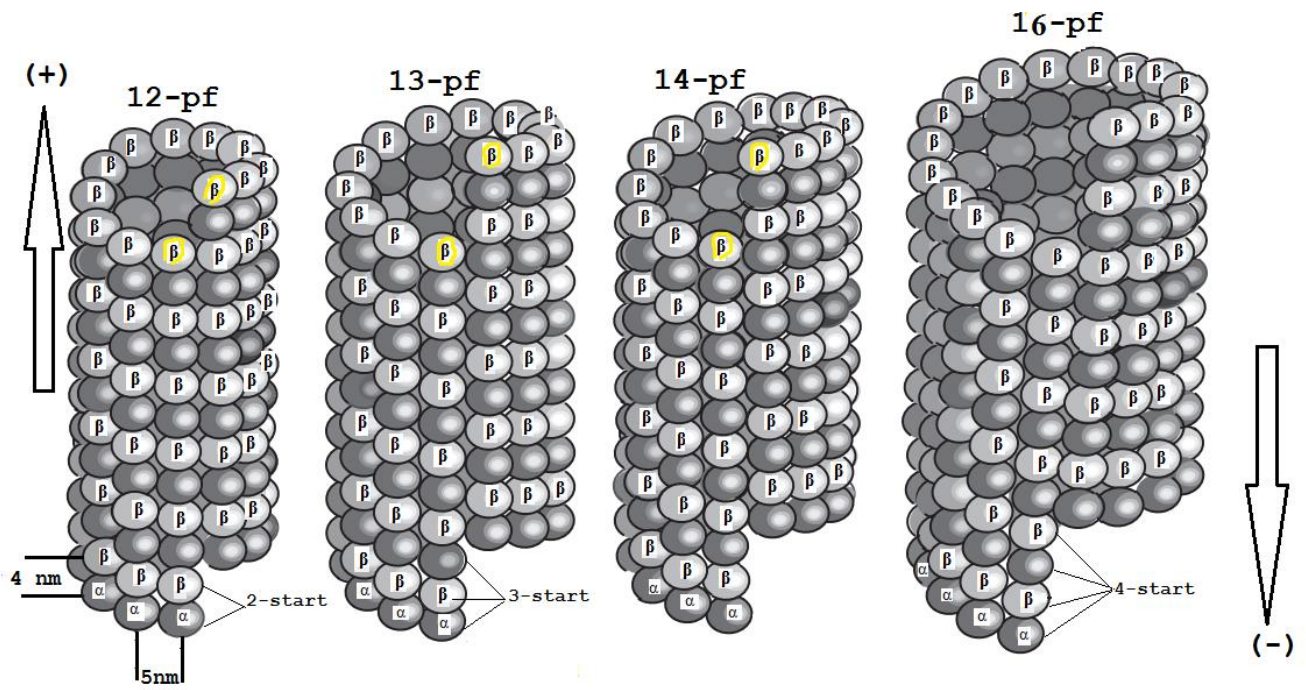

Figure 2. the schematic images of various microtubules including "12-16" proto-filaments (pf)

Two major structures of $\alpha \beta$-tubulin are known that the first one is GDP-tubulin in straight antiparallel proto-filaments stabilized by "Taxol" and the second is the curved structure of two head to tail GDPtubulin dimers in complex with the stathmin-like domain (RB3-SLD) (Fig.3). (Charbaut, 2001; Curmi, 2000).

The structures of tubulins in microtubules are related to the straight zinc-sheet structures. Monomers in adjacent proto-filaments serialize a set of shallow helices that for 13-protofilament microtubules three shallows run in parallel. This situation causes a suitable flexibility in the bonds between adjacent heterodimers (Hanash, 1998; Price, 2000).

The microtubules -associated motor proteins, such as dynein and kinesin can be run for long distances along a microtubule when there are 14 proto-filamentsn (Belmont, 1996). In more or fewer than 14 protofilaments, the structure might be rotate somewhat, so that the proto-filaments twisted slowly around the microtubule axis (Hirokawa, 1996).

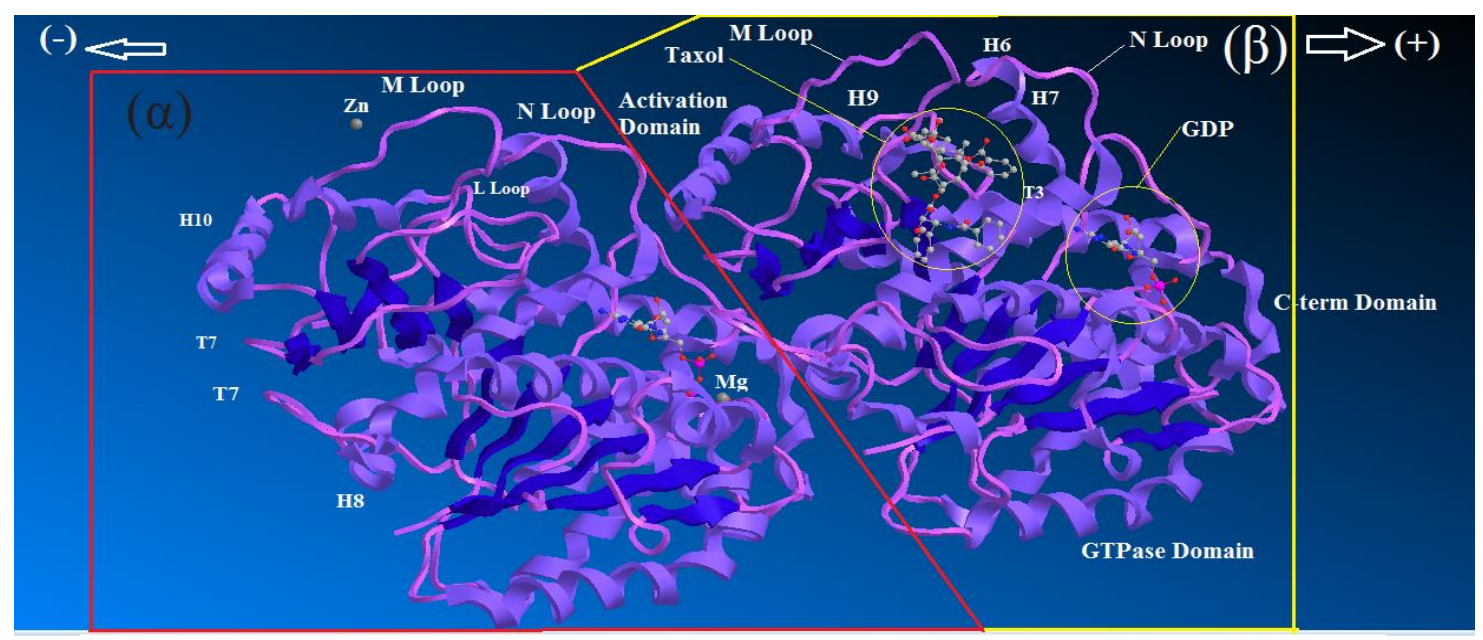

Figure 3. The structure designed by electron crystallography in complex with Taxol. The guanosine triphosphate "GTPase" domain, the activation domains and the core helix connected to two globular domains in each monomer on the external surfaces are shown. GTP is sandwiched between $\alpha$ and $\beta$ tubulin subunits of each heterodimer and in $\square$-tubulin, this pocket are occupied by the extended L-loop. 
Ravelli et al. (Ravelli, 2003) exhibited some important data about the conformational changing of microtubules structures through X-ray crystallography (Nogales, 1998). The monomers have a pair of spherical domains which the larger domain, containing the N-terminal half of the polypeptide (Vale, 2003) A binding site for "Taxol" is located on the second domain of $\alpha \beta$-tubulins, which has sufficient contact with the core helix and also on the opposite side has contact with a nucleotide base. The Cterminal end of each tubulin polypeptide makes two long helices and these residues are suitable for isoform recognition through tubulin binding proteins. As it has been shown in Fig.3, the long coil loop of globular domain is attached in lateral contact to the proto-filament inside the microtubule. In addition there is common agreement that the "M-loop" of one proto-filament make contact with the GTPase domain. In some location the proto-filament makes a ring through bending at all of the interfaces between monomers (Castle, 2017).

Stathmin interacts with $\alpha, \beta$-tubulin for forming a ternary complex which tubulins are able to switch between a curved structure of this complex including RB3 protein and a straight microtubule-like structure. By this study the kinetic, potential, total and thermodynamic assemblies and dis-assemblies have been done by GTP hydrolysis in view point of Monte Carlo simulation. The microtubule-associated proteins (MAPs) of tubulin-GDP proto-filament helixes have been indicated with dimer curvatures. This phenomenon indicates a proposition that the free GTP- tubulin dimers are curved similarly to tubulin rings and is driven into the straight conformation through the microtubule. So the GTP $\gamma$-phosphate only lowers the unfavorable free energies differences between the curved and the straight form. Consequently, in the allosteric model GTP binding would induce a straighter conformation pre-structured in solution for lateral interactions whereas in the lattice model $\alpha \beta$-tubulin adopts a microtubule incompatible, curved conformation independent of the nucleotide state (Piehl, 2004).

\section{STATHMIN-MICROTUBULES INTERACTIONS}

Stathmin interacts with two molecules of dimeric $\alpha, \beta$-tubulin to form a tight ternary complex which one mole of stathmin binds to two moles of tubulin dimers through the SLD. Tubulin is able to switch between a curved structure in complex with the stathmin-like domain of the RB3 protein and a straight microtubulelike structure. The proto-filament curvature and disassembly has done via GTP hydrolysis. The first opinion for GTP was thought that it would allosterically induce a straight conformation of tubulin subunits thorough-paced of microtubule assembly while the GDP would induce a curved conformation approving disassembly. The microtubule-associated proteins (MAPs) of tubulin-GDP proto-filament spirals have indicated different intra- and inter-dimer curvatures. However, this type of allosteric mechanism is challenged by the findings of curved structures of GTP-bound $\gamma$-tubulin. This evidence led to a proposition that the free GTP-tubulin dimer is curved similarly to tubulin rings and is driven into the straight conformation by the microtubule (opposed to what was previously thought). So the GTP $\gamma$-phosphate only lowers the unfavorable free energy difference between the curved and the straight form. Consequently, in the allosteric model GTP binding would induce a straighter conformation pre-structured in solution for lateral interactions whereas in the lattice model $\alpha \beta$-tubulin adopts a microtubule incompatible, curved conformation independent of the nucleotide state(Naghsh, 2018).

It should me important to discuss of the GTP hydrolysis mechanism for destabilizing the microtubule lattice. To provide some answers to this question, Alushin et al., exhibited a structural study for comparing high-resolution cryo-EM reconstructions of GMPCPP microtubules and GDP microtubules (Andersen, 1997).

It shows that GTP hydrolysis induces a compression at the linear interface between dimers, immediately over the exchangeable nucleotide-binding site. This compression is amalgamated by conformational changes in $\alpha$-tubulin. In contrast, lateral contacts between $\alpha \& \beta$ tubulins were basically unchanged in the different nucleotide states. These understanding suggest that GTP hydrolysis introduces strain into the

Nexo Revista Científica / Vol. 33, No. 01, pp. 22-35 / Junio 2020 


\section{Farnoush Naghsh et al.}

lattice, but how this strain affects the strength of longitudinal and lateral bonds to destabilize the microtubule remains unknown (Rusan, 2002).

In this works 16 main sections have considered for investigation of bonded and non-bonded interaction between Stathmin with microtubules (Belmont, 1996). Although the bonded situations and the GTP hydrolysis essentially are important for the proto-filament curvature and disassembly, the no bonded interaction helps to this processing in other side. More over this kind of non-bonded interaction provides the dynamic behavior for this phenomenon. It now seems clear that changes in the curvature of $\alpha \beta$-tubulin are fundamental to microtubule dynamics and the regulatory activities of microtubule-associated proteins (MAPs) during microtubule polymerization (Odde, 1995).

\section{QM/MM SIMULATION}

A model of Tubulins -stathmin-like domain complex whit a radius of $20 \mu \mathrm{m}$ and a height of $0.4 \mu \mathrm{m}$ for a volume of approximately $900 \mu \mathrm{m}^{3}$ has been simulated where MTs are nucleated from a defined number of sites located in the center of a cylinder (Jalilian, 2015).

The simple structure emulators the basic area of a generic cell binding for the minimum slip where MTs and Tubulins -stathmin-like domain complex (T-SLD) are dynamically measured. The concentrations of total tubulins were basically set between 30-35 $\mu \mathrm{M}$. For increasing the efficiency of simulations the number of nucleation site were modeled to 400, which also collected the maximum number of T-SLD. Additional presumptions have been considered as : (1) Tubulins -complete T-SLD de-polymerization immediately opens up that nucleation site for a new nucleation event (Leibler, 1993). (2) all T-SLD remain associated with their nucleation site until they completely de-polymerize and do not bend during confliction with the cell margin; (3) T-SLD de-stabilization is dependent on free tubulin concentration; (4) any T-SLD de-stabilization reaching the cell boundary undergoes a catastrophe. Simulations, with time step $=1 \mathrm{~s}$ obeyed the general sequences as: (1) available places are checked for nucleation based on the given probability, (2)T-SLD with a velocity determined by free tubulin concentration, (3) stabilization /destabilization of T-SLD can remain in a catastrophe, thereby switching to a shortening state. T-SLD that achieves the cell boundary will move to a shortening state. (4) Shortening T-SLD can continue to shorten or undergo a liberation phenomenon. Output from this modeling are including, number and lengths, free tubulin concentration, the length of a single T-SLD during the simulation and thermodynamic parameters. Common data and values applied for simulating the interphase T-SLD array. Nucleation rate were estimated based on previous work from the centrosome divided by the $450-500$ potential sections. Total tubulin concentrations were calculated as

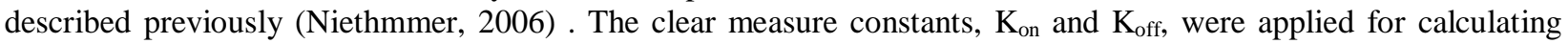
assembling and de-assembling measuring as a function of free tubulin concentration. The initial parameters tested based on interphase LLCPK1 cells. In addition end dynamic instability based on Monte Carlo method is listed in Table 1. Fig.2 .

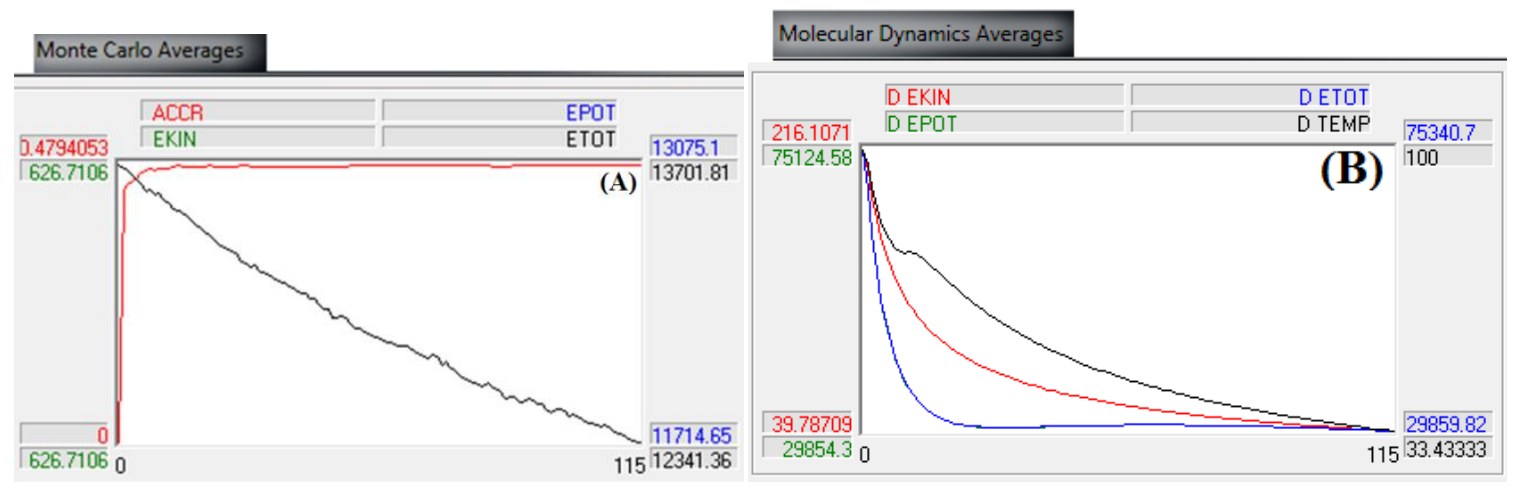

Figure 4. Monte Carlo \& Molecular dynamic simulation of T-SLD in 6 stages

Nexo Revista Científica / Vol. 33, No. 01, pp. 22-35 / Junio 2020 
Table 1. Energies sets for T-SLD end dynamic instability

\begin{tabular}{|l|l|l|l|l|}
\hline $\begin{array}{l}\text { Simulation } \\
\text { Temperature }\end{array}$ & $\begin{array}{l}\text { Potential } \\
\mathrm{kcal} / \mathrm{mol}\end{array}$ & $\begin{array}{l}\text { Kinetic } \\
\mathrm{kcal} / \mathrm{mol}\end{array}$ & $\begin{array}{l}\text { Total } \\
\mathrm{kcal} / \mathrm{mol}\end{array}$ & $\begin{array}{l}\text { Various } \\
\text { Stets }\end{array}$ \\
\hline 300 & 13075.1 & 626.7 & 13701.8 & $\mathrm{~A}$ \\
\hline 305 & 75340.7 & 216.1 & 75340.7 & $\mathrm{~B}$ \\
\hline 307 & 9569.5 & 313.3 & 9569.5 & $\mathrm{C}$ \\
\hline 310 & 5717.1 & 216.1 & 5717.1 & $\mathrm{D}$ \\
\hline 311 & 5378.2 & 216.1 & 5378.3 & $\mathrm{E}$ \\
\hline 312 & 5341.1 & 324.1 & 5341.1 & $\mathrm{~F}$ \\
\hline
\end{tabular}

As shown in Fig.2A, the distributions of T-SLD lengths forms a tightly exponential, where T-SLD ends is limited to an area near the edges, based on defined by the cell radius. The length of one molecule T-SLD is exhibited in Fig. 2B. Consistent with the distribution of all T-SLD ends, the end of this single T-SLD spends maximum of its time close the cell boundary. Fig. 2C exhibits a simulation run for fewer steps to show the early steps in T-SLD assembly for a single T-SLD. Slower speed, as tubulins are combined into T-SLD, were trivial through changes in the slope on

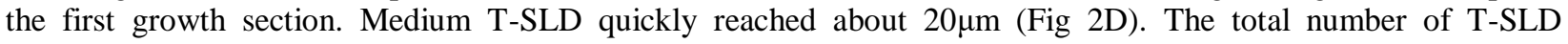
increased for 4500 microtubules via around 4,000 s. We applied the simulations of free tubulin concentration in a steady state amounts through the Fig $2 \mathrm{E}$ and the standard deviations of those values also in Fig.2F.

\section{STATHMIN AND MICROTUBULE DYNAMICS}

Microtubules exist in a situation of continuous transition between two phases of polymerization and depolymerization which is based on dynamic instabilities with a stochastic mechanism which this phenomenon is known as catastrophe (Fig.5).

In intermediate structure, microtubule is long and stable with its dynamic relatively slow. Belmont [29] supposed a model to exhibited stathmin exerts effects via increasing the rate of catastrophe and consequently an explanation in which the microtubule-depolymerized .The mechanism is based on stathmin binds two un-polymerized tubulins in ternary stathmin-tubulin complexes (Fig.5).

The tubulin-sequestering activities of the stathmin prevent any growth of microtubule through tubulin polymerization. The catastrophe-promoting activities are confirmed for occurring at the ends of polymerization and also exhibit how does stathmin binds tubulin heterodimers at the microtubule ends for increasing catastrophe via a GTP hydrolysis-dependent mechanism structure of the complex of tubulin and also the stathmin-like domain (SLD) of RB3.

The tubulins subunits in the complex are associated head-to-tail in a curved conformation. The same group recently extended these observations by showing that the curved complex is capped by the aminoterminal region of the SLD domain.

This prevents the incorporation of the complex into polymerized microtubules. These investigations exhibit that stathmin are able to bind both polymerized and un-polymerized tubulins and is able to exclude the polymerization towards a stable microtubule. 

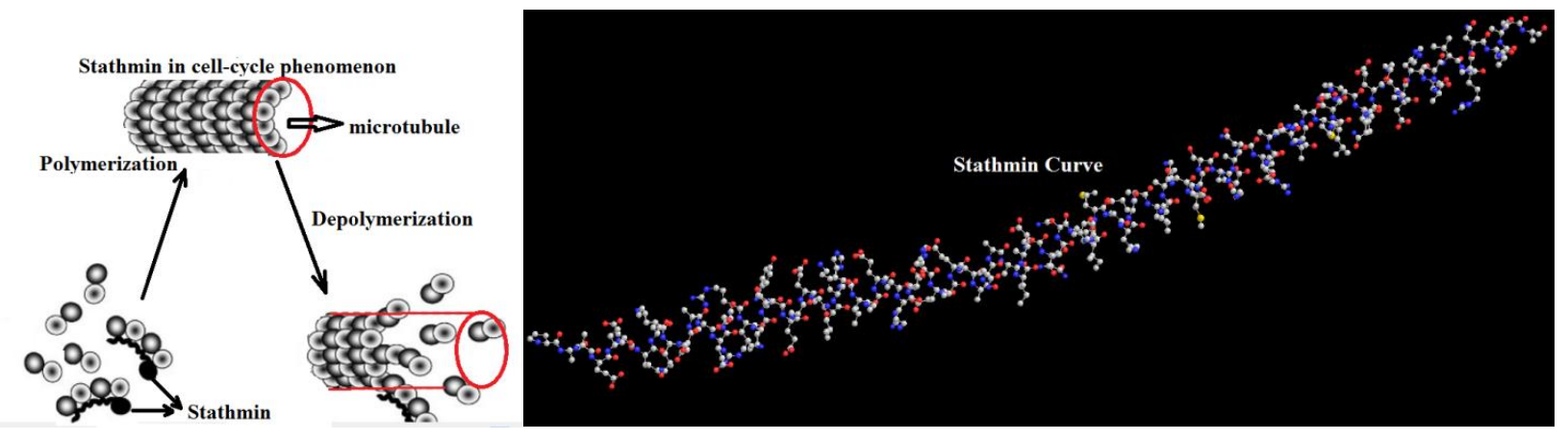

Figure 5. Model for the role of stathmin in the regulation of microtubule dynamics

\section{ESTIMATION OF KINETIC AND FREE ENERGIES}

In the kinetic reaction the rate constant of association and dissociation are as $K_{a}$ and $K_{d}$, respectively. The free energy for the association reaction is $\Delta G_{a}=-R T \operatorname{Ln} K$ with the relation of $K=\frac{K_{a}}{K_{d}}$. For simplicity it can be supposed that the $K_{a}$, is equal for all sites, therefore a fixed-geometry binding site is applied due to highest affinity of tubulin-GTP interaction comprising to the isolated site. The $K=\frac{K_{a}}{K_{d}}$ values can be calculated using estimated free energies values of individual bonds with definition of association and dissociation sites. The affinities of the tubulins dimer for a microtubule end then depends upon the number of contacts formed. The free energies for the binding of one molecule of Tubulin-GTP at the especial sites may be obtained as the sum of the free energies for individual subunit-subunit interactions between tubulin monomers. The binding of a molecule of Tubulin-GTP to a typical site may be formally regarded as involving free energy terms (Fig. 1)

\section{COMPUTATIONAL DETAILS}

We have simulated a part of microtubule systems including $\alpha \beta$-tubulin heterodimer and stathmin through QM/MM simulation using Monte Carlo method. Each system was composed of 16 sections of stathmin molecules including interaction with tubulin. Thermodynamic averages for molecular properties were determined from Monte Carlo methods, as can minimum-energy structures. At finite temperature, clusters have finite vapor pressures, and particular cluster sizes are typically unstable to evaporation. Introducing a constraining potential enables one to define clusters of desired sizes. Composed of 16 sections of stathmin molecules were carried out with the simulation microtubules. The pressure was maintained by a variant of the extended system formalism, the Langevin Piston algorithm, which reduces oscillations in the cell parameters. The temperature was maintained at $300 \mathrm{~K}$, well is the body temperature and identical to the relevant experiments.Configurations of $\alpha \beta$-tubulin heterodimer and stathmin consistent with a mean field were generated by Monte Carlo (MC) simulation, with field values adjusted to obtain agreement with experimental order parameters. In this investigation, differences in force field are illustrated by comparing the calculated energy by using force fields AMBER and OPLS. Furthermore Hyper-Chem professional release 7.01 is used for the calculations. The final parameterization of stathmin was computed using selfconsistent field calculations in order to find the optimal starting geometry, as well as the partial charges. We employed density functional theory with the van der Waals density functional to model the exchangecorrelation energies of $\alpha \beta$-tubulin heterodimer. All optimization of 16 section of stathmin monomer were performed by Gauessian and GAMESS-US package. We have mainly focused on getting the results from DFT methods such as m062x, m06-L, and m06 for the $\alpha \beta$-tubulin heterodimer. The m062x, m06-L and m06-HF are rather new DFT functional with a good correspondence in non-bonded calculations between tubulin heterodimer and are useful for the energies of distance between two fragments in phospholipids. For non-covalent interactions, the B3LYP method is unable to describe van der Waals microtubules

Nexo Revista Científica / Vol. 33, No. 01, pp. 22-35 / Junio 2020 
systems by medium-range interactions such as the interactions of two tubulins. So the ONIOM methods including 3 levels of 1-high calculation $(\mathrm{H})$, 2-medium calculation $(\mathrm{M})$, and 3-low calculation (L) have been performed in our study for calculating the non-bonded interactions between tubulins. The ab-initio and DFT methods are used for the model system of the ONIOM layers and the semi empirical methods of Pm6 (including pseudo=lan12) and Pm3MM are used for the medium and low layers, respectively. The semi empirical methods have been used in order to treat the non-bonded interactions between two tubulins.B3LYP and the most other popular functional are insufficient to illustrate the exchange and correlation energy for distant non-bonded medium-range systems correctly. Moreover, some recent studies have shown that inaccuracy for the medium-range exchange energies leads to large systematic errors in the prediction of molecular properties Geometry optimizations and electronic structure calculations have been carried out using the m06 (DFT) functional(Dang, 2020). This approach is based on an iterative solution of the Kohn-Sham equation of the density functional theory in a plane-wave set with the projector-augmented wave pseudo-potentials. The Perdew-Burke-Ernzerhof (PBE) exchange-correlation (XC) functional of the generalized gradient approximation (GGA) is adopted (Ardalan, 2014). The optimizations of the lattice constants and the atomic coordinates are made by the minimization of the total energy. The charge transfer and electrostatic potential-derived charge were also calculated using the MerzKollman-Singh, chelp, or chelpG (MONAJJEMI, 2010-2018)

\section{RESULT AND DISCUSSIONR}

Monte Carlo simulation has been applied to study dynamic instability of the microtubule length of our model based on the papers. In this method one-dimensional microtubule is fixed at one of the two and simulated while the opposite end is allowed for growing in random situation. In this model at each step one tubulin has been added to the length for growing microtubule length. Computationally this can be done through generating a uniform random number between $(0,1)$. Comparing the data for dynamical instabilities among parameter sets exhibited that rates of elongation and shortening varies to the small degrees. For testing how the differences data among the parameters contribute to the overall microtubule arrays, it can be simulated with those parameters from one set and basically switched that data at a time to that from the other set. It might be considered the effect of stathmin concentration gradient for formation of microtubule length. So the model of quasi-one-dimensional constriction of microtubules has been selected. In this model, the microtubule formation switches among assemblies states and dis-assemblies with the random variables of Monte Carlo approach (Le, 2019). A transition frequency $f_{t}$ has been defined for assembly states to disassembly situation of catastrophe and $f_{t^{-1}}$ has been defined from dis-assemblies to assembly. Based on several parameters like formation and constriction velocities, tubulin concentration have to describe through the simplest stochastic model of field equations based on Leibler work to study this matter using Monte Carlo simulation of microtubule length. This model consist of a cell including free $\alpha \beta$-tubulins and stathmin which are distributed uniformly. The accessibility of free $\alpha \beta$-tubulins in the cell pertains on the concentration of the stathmin due to each stathmin binds to two $\alpha \beta$-tubulins towards three-meric structure. However, these situations of stathmin proteins are weakened around mitotic chromosome because of stathmin's phosphorylation. It might be supposed that from the centrioles towards the chromatin position, the activities of stathmin are uniform till a certain distance, and then there is a gradual inhibition of stathmin activities which are approximately zero at the chromatin. As a result, one finds a gradient of stathmin-tubulin interaction as one move towards the chromatin as reported by Niethmmer experimentally. Based on our previous works we simulated these systems. At any immediate of time microtubules end are in one of the two situation, length and or simplifying. In this simulation a regular steps of time " $\mathrm{t}$ " it might be possible for adding or subtracting one tubulin length for growing or simplifying microtubules elongation. If $f_{t}$ and $f_{t^{-1}}$ are the transitions frequencies for catastrophe and rescue, respectively then the normalized equations of those frequencies can be written as: $f_{\text {catastrophe }}=$ $\frac{f_{t}}{f_{t}+f_{t^{-1}}}$ and $f_{\text {rescue }}=\frac{f_{t^{-1}}}{f_{t}+f_{t^{-1}}}$. The microtubule elongation at a especially immediate of time will be in length situation or simplifying states if the random numbers are less than the normalized transition frequencies for catastrophe, $f_{t}$ or rescue, $f_{t^{-1}}$. Obviously, it must be supposed the transitions to be

Nexo Revista Científica / Vol. 33, No. 01, pp. 22-35 / Junio 2020 


\section{Farnoush Naghsh et al.}

instantaneous and with a definition of critical length, $L_{\text {critical }}, f_{\text {catastrophe }}$ and $f_{\text {rescue }}$ (with an exponential function) are constant.

In this position the velocities of growth is $V_{\text {growth }}$ and for shrinkage $V_{\text {shrinkage }}$ for the microtubules (Table.3).

Table3. Parameter sets for MT plus end dynamic instability

\begin{tabular}{|l|l|l|l|l|l|l|}
\hline No. & \multicolumn{1}{|c|}{$\begin{array}{c}V_{\text {growth }} \\
\mu m s^{-1}\end{array}$} & $\begin{array}{c}V_{\text {shrinkage }} \\
\mu m s^{-1}\end{array}$ & $\begin{array}{c}K_{a} \\
s^{-1}\end{array}$ & $\begin{array}{c}K_{d} \\
s^{-1}\end{array}$ & $k G$ \\
\hline 1 & 0.223 & 0.155 & 0.055 & 0.067 & 0.82 & -494.97 \\
\hline 2 & 0.199 & 0.167 & 0.046 & 0.078 & 0.59 & -1316.1 \\
\hline 3 & 0.213 & 0.188 & 0.064 & 0.081 & 0.79 & -587.94 \\
\hline 4 & 0.191 & 0.149 & 0.057 & 0.066 & 0.86 & -376.18 \\
\hline
\end{tabular}

\section{CONCLUSION}

Microtubules are demonstrated as straight macromolecules consist of the linear chains of tubulin subunits in the length without any incorporating molecular details of tubulin dimers, protofilament or other structures. It has been calculated a correct dimension around $10^{-6}$ meter of microtubules length consist of around 1650 tubulin dimers. Microtubule growth rate is related to the soluble tubulin dimer concentration and for all results shown here, simulation of any single condition was run 5-10 times. For each simulation it has been recorded values number, average length and free tubulin concentration

\section{REFERENCES}

Akhmanova, A., and M.O. Steinmetz. (2015). Control of microtubule organization and dynamics: two ends in the limelight. Nat. Rev. Mol. Cell Biol.16, 711-726. https://doi.org/10.1038/nrm4084

Andersen, S.S., Ashford, A.J., Tournebize, R., Gavet, O., Sovel, A., Hyman, A.A., Karsenti, E., (1997) Mitotic chromatin regulates phosphorylation of stathmin/Op18. Nature 389, 640-643.

Ardalan, T.; Ardalan, P.; Monajjemi, M. (2014) Nano theoretical study of a C 16 cluster as a novel material for vitamin C carrier. Fullerenes Nanotubes and Carbon Nanostructures, 22, 687-708, https://doi.org/10.1080/1536383X.2012.717561.

Brouhard, G.J., and L.M. Rice. (2014). The contribution of $\alpha \beta$-tubulin curvature to microtubule dynamics. J. Cell Biol. 207:323-334. https://doi.org/ 10.1083/jcb.201407095

Belmont, LD, Mitchison TJ, (1996), Identification of a protein that interacts with tubulin dimers and increases the catastrophe rate of microtubules. Cell , 84:623-631.

Belmont, L.D and Mitchison, T.J. (1996) Identification of a protein that interacts with tubulin dimers and increases the catastrophe rate of microtubules. Cell, $84,623-631$.

Castle, B.T., McCubbin, S., Prahl, L.S., Bernens, J.N., Sept, D., Odde, D.J. (2017) Mechanisms of kinetic stabilization by the drugs paclitaxel and vinblastine. Mol Biol Cell. 28, 1238-1257. https://doi.org/10.1091/mbc. E16-08-0567 PMID: 28298489

Nexo Revista Científica / Vol. 33, No. 01, pp. 22-35 / Junio 2020 
Clément, M.J., Jourdain, I., Lachkar, S., Savarin, P., Gigant, B., Knossow, M., Toma, F., Sobel, A., Curmi, P.A (2005), N-terminal stathmin-like peptides bind tubulin and impede microtubule assembly. Biochemistry, 44 (44), 14616-25. doi:10.1021/bi0512492. PMID 16262261.

Chen, Y., and W.O. Hancock. (2015). Kinesin-5 is a microtubule polymerase. Nat.Commun. 6, 8160. https://doi.org/10.1038/ncomms9160

Charbaut E, Curmi PA, Ozon S, Lachkar S, Redeker V, Sobel A, (2001) Stathmin family proteins display specific molecular and tubulin binding properties. J Biol Chem, 276:16146-16154.

Curmi PA, Nogues C, Lachkar S, Carelle N, Gonthier MP, Sobel A, Lidereau R, Bieche I (2000) Overexpressioin of stathmin in breast carcinomas points out to highly proliferative tumours. Br J Cancer $82: 142-150$

Dang, D. M. T., d Monajjemi, M., Mollaamin, F., Dang, C.M., (2020) Simulation of droplet ejection based on electromechanical parameters \& chemical condition for controlling inkjet printing devices Biointerface Research in Applied chemistry , Volume 10, Issue 3, 5361 - 5368, https://doi.org/10.33263/BRIAC103.361368

Garvalov, et al. (2006). Luminal partiles within cellular microtubules. J. Cell Biol. 174, 759-765

Guesdon, A., F. Bazile, R.M. Buey, R. Mohan, S. Monier, R.R. García, M. Angevin, C. Heichette, R. Wieneke, R. Tampé, et al. (2016) EB1 interacts with outwardly curved and straight regions of the microtubule lattice. Nat. Cell Biol. 18:1102-1108. https://doi.org/10.1038/ncb3412

Gupta, K.K., E.O. Alberico, I.S. Näthke, and H.V. Goodson. (2014) Promoting microtubule assembly: A hypothesis for the functional significance of the +TIP network. BioEssays. 36, 818-826.

https://doi.org/10.1002/bies 201400029.

Hepler, P.K., (2016) The Cytoskeleton and Its Regulation by Calcium and Protons. Plant Physiol. 170, 322. https://doi.org/10.1104/pp.15.0150626722019

Hanash SM, Strahler JR, Kuick R, Chu EH, Nichols D: (1998), Identification of a polypeptide associated with the malignant phenotype in acute leukemia. J Biol Chem, 263:12813-12815.

Hirokawa, N. (1998). Kinesin and dynein superfamily proteins and the mechanism of organelle transport. Science 279, 519-526.

Jalilian, H.; Monajjemi, M. (2015) Capacitor simulation including of X-doped graphene (X = Li, Be, B) as two electrodes and $(\mathrm{h}-\mathrm{BN}) \mathrm{m}(\mathrm{m}=1-4)$ as the insulator. Japanese Journal of Applied Physics, 54, 085101-7.

Le, C.M.T., Monajjemi, M., Pham, T.T., Mollaamin, F., Dang, C.M., (2020) Diffusion \& concentration effect of $\mathrm{Li} / \mathrm{Li}+$ to the efficiency of LIBs, Biointerface Research in Applied chemistry, Volume 10, Issue 2, 5076 - 5084, https://doi.org/10.33263/BRIAC102.076084

Leibler, S and Dogterom, M., (1993) Physical aspects of the growth and regulation of microtubule structure. Phys. Rev. Lett. 70, 1347-1350.

Le, C.M.T., Mollaamin, F., Dang, D.M.T., Monajjemi, M., Dang, C.M., (2019), Realistic simulation of the polymers in inkjet process: the investigation of physical phenomena in the ejection of a droplet, 
Farnoush Naghsh et al.

Biointerface Research in Applied chemistry, Volume 9, Issue 3, 3949 - 3955, https://doi.org/10.33263/BRIAC93.949955

Le, C.M.T., Monajjemi, M., Pham, T.T., Mollaamin, F., Dang, C.M., (2019), Simulation \& modelling of dilute solutions in drop-on-demand inkjet printing: a review, Biointerface Research in Applied chemistry, Volume 9, Issue 6, 4474 - 4484, https://doi.org/10.33263/BRIAC96.474484

Mollaamin, F. Monajjemi, M. (2012) DFT outlook of solvent effect on function of nano bioorganic drugs. Physics and Chemistry of Liquids, 50, 596-604, https://doi.org/10.1080/00319104.2011.646444

Mollaamin, F.; Gharibe, S.; Monajjemi, M. (2011) Synthesis of various nano and micro ZnSe morphologies by using hydrothermal method. International Journal of Physical Sciences 2011, 6, 14961500.

Monajjemi, M.; Hosseini, M.S. (2013) Non bonded interaction of B16 N16 nano ring with copper cations in point of crystal fields. Journal of Computational and Theoretical Nanoscience, 10, 2473- 2477.

Monajjemi, M. (2015) Non-covalent attraction of B N and repulsion of B $\mathrm{N}$ in the $\mathrm{B} \mathrm{N}$ ring: a quantum rotatory due to an external field. Theoretical Chemistry Accounts, 134, 1-22, https://doi.org/10.1007/s00214-015-1668-9.

Monajjemi, M.; Naderi, F.;Mollaamin, F.; Khaleghian, M. (2012), Drug design outlook by calculation of second virial coefficient as a nano study. Journal of the Mexican Chemical Society 2012, 56, 207-211.

Monajjemi, M.; Bagheri, S.; Moosavi, M.S. (2015) Symmetry breaking of B2N(-,0,+): An aspect of the electric potential and atomic charges. Molecules, 20, 21636-21657, https://doi.org/10.3390/ molecules201219769.

Monajjemi, M.; Mohammadian, N.T. (2015) S-NICS: An aromaticity criterion for nano molecules. Journal of Computational and Theoretical Nanoscience 2015, 12, 4895-4914, https://doi.org /10.1166/jetn.2015.4458.

Monajjemi, M.; Ketabi, S.; Hashemian Zadeh, M.; Amiri, A. (200) Simulation of DNA bases in water: Comparison of the Monte Carlo algorithm with molecular mechanics force fields. Biochemistry (Moscow), $71,1-8$.

Monajjemi, M.; Lee, V.S.; Khaleghian, M.; Honarparvar, B.; Mollaamin, F. (2010), Theoretical Description of Electromagnetic Nonbonded Interactions of Radical, Cationic, and Anionic NH2BHNBHNH2 Inside of the B18N18 Nanoring. J. Phys. Chem C, 114, 15315, http://dx.doi.org/10.1021/jp104274z.

Monajjemi, M.; Boggs, J.E. (2013) A New Generation of BnNn Rings as a Supplement to Boron Nitride Tubes and Cages. J. Phys. Chem. A, 117, 1670-1684, http://dx.doi.org/10.1021/jp312073q.

Monajjemi, M. (2013) bonded interaction between BnNn (stator) and BN B (rotor) systems: A quantum rotation in IR region. Chemical Physics, 425, 29-45, https://doi.org/10.1016/j.chemphys.2013.07.014.

Monajjemi, M.; Robert, W.J.; Boggs, J.E. (2014) NMR contour maps as a new parameter of carboxyl's $\mathrm{OH}$ groups in amino acids recognition: A reason of tRNA-amino acid conjugation. Chemical Physics, 433, 1-11, https://doi.org/10.1016/j.chemphys.2014.01.017. 
Farnoush Naghsh et al.

Monajjemi, M. (2012) Quantum investigation of non-bonded interaction between the B15N15 ring and BH2NBH2 (radical, cation, and anion) systems: a nano molecularmotor. Struct Chem, 23, 551-580, http://dx.doi.org/10.1007/s11224-011-9895

Monajjemi, M. (2014) Metal-doped graphene layers composed with boron nitride-graphene as an insulator: a nano-capacitor. Journal of Molecular Modeling 20, 2507, https://doi.org/10.1007/s00894-0142507-y.

Monajjemi M. (2017) Graphene/(h-BN)n/X-doped raphene as anode material in lithium ion batteries $(\mathrm{X}=$ Li, Be, B AND N). Macedonian Journal of Chemistry and Chemical Engineering, 36, 101-118, http:// dx.doi.org /10.20450/mjcce.2017.1134.

Monajjemi, M. (2015) Cell membrane causes the lipid bilayers to behave as variable capacitors: A resonance with self-induction of helical proteins. Biophysical Chemistry, 207, 114-127, https://doi.org/10.1016/j.bpc.2015.10.003.

Monajjemi, M. (2018) Study of CD5+ Ions and Deuterated Variants (CHxD(5-x)+): An Artefactual Rotation. Russian Journal of Physical Chemistry a, 92, 2215-2226.

Monajjemi, M. (2017) Liquid-phase exfoliation (LPE) of graphite towards graphene: An ab initio study. Journal of Molecular Liquids, 230, 461-472.

Monajjemi, M., (2019) Molecular biology's symphony orchestra from DNA to ribosome: a sonification from gene to protein, Biointerface Research in Applied chemistry, Volume 10, Issue 4, 5679 - 5688. https://doi.org/10.33263/BRIAC104.679688

Monajjemi, M., Mollaamin, F., Shojaei, S., (2020) An overview on Coronaviruses family from past to Covid-19: introduce some inhibitors as antiviruses from Gillan's plants, Biointerface Research in Applied chemistry, Volume 10, Issue 3, 5575 - 5585. https://doi.org/10.33263/BRIAC103.575585

Monajjemi, M., Shahriari, S., Mollaamin, F., (2020) Evaluation of Coronavirus Families \& Covid-19 Proteins: Molecular Modeling Study, Biointerface Research in Applied chemistry, Volume 10, Issue 5, 6039 - 6057. https://doi.org/10.33263/BRIAC105.60396057

Monajjemi, M., Naghsh, F., Mollaamin, F., (2020) Bio-Lipid Nano Capacitors: Resonance with Helical Myeline Proteins, Biointerface Research in Applied chemistry, Volume 10, Issue 6, 6695 - 6705, https://doi.org/10.33263/BRIAC106.66956705

Monajjemi,M., Mollaamin, F., (2020) Bio-capacitor consist of insulated myelin-sheath and uninsulated node of Ranvier: a bionano-antenna, Biointerface Research in Applied chemistry, Volume 10, Issue 1, 4956 - 4965, https://doi.org/10.33263/BRIAC101.956965

Monajjemi, M., (2019), Artificial intelligence \& self-consistent sonification method for converting DNA sequence to music, Biointerface Research in Applied chemistry, Volume 9, Issue 6, 4494 - 4501, https://doi.org/10.33263/BRIAC96.494501

Mollaamin, F., Pham, T.T., Dang , D.M.T., Monajjemi, M., Dang, C.M., (2019) Modelling and Controlling of ion transport rate efficiency in Proton exchange membrane (PEMFC), alkaline (AFC), direct methanol (DMFC), phosphoric acid (PAFC), direct forming acid(DFAFC) and direct carbon (DCFC) fuel cells, Biointerface Research in Applied chemistry, Volume 9, Issue 4, 4050 - 4059, https://doi.org/10.33263/BRIAC94.050059

Nexo Revista Científica / Vol. 33, No. 01, pp. 22-35 / Junio 2020 
Farnoush Naghsh et al.

Monajjemi, M., (2019) ,C-NMR sonification of human insulin: a method for conversion of amino-acid sequences to music notes, Biointerface Research in Applied chemistry, Volume 9, Issue 4, 4077 https://doi.org/10.33263/BRIAC94.077084

Monajjemi, M., (2019), Molecular vibration of dopamine neurotransmitter: a relation between its normal modes and harmonic notes, Biointerface Research in Applied chemistry, Volume 9, Issue 3, 3956 - 3962, https://doi.org/10.33263/BRIAC93.956962

Naghsh, F., Monajjemi, M., Zare, K, (2018), A conceptual model of microtubules as a macrobiological molecule and Quantum Consciousness, Biointerface Research in Applied chemistry, Volume 8, Issue 6, $3758-3763$

Nogales, E., Downing, K. H., Amos, L. A., and Löwe, J (1998). Tubulin and FtsZ form a distinct family of GTPases. Nat. Struct. Biol. 5, 451-458.

Niethmmer, P., Bastiaens, P and Karsenti, E., (2004) Stathmin-tubulin interaction gradients in motile and mitotic cells. Science, 303, 1862-1866

Ozon S, Maucuer A, Sobel A: The stathmin family. (1997) Molecular and biological characterization of novel mammalian proteins expressed in the nervous system. Eur J Biochem, 248:794-806.

Odde, D.J and Buettner, H.M., (1995) Time series characterization of simulated microtubule dynamics in nerve growth cone. Ann. Bio. Eng. 23, 268-286.

Piehl, M., Tulu, U.S., Wadsworth, P and Cassimeris, L., (2004) Centrosome maturation: Measurement of microtubule nucleation throughout the cell cycle by using GFP-tagged EB1. Proc Natl Acad Sci (USA). 101, 1584-1588.

Pham1, T.T., Monajjemi, M., Mollaamin, F., Dang, C.M., (2020), Advanced materials for family of fuel cells: a review of polymer electrolyte membrane, Biointerface Research in Applied chemistry, Volume 10, Issue 1, 4853 - 4863, https://doi.org/10.33263/BRIAC101.853863

Pham, T.T., Monajjemi, M., Dang, D.M.T., Mollaamin, F., Khakpour, A., Dang, C.M., (2019), An overview of bio-interface electrolyte and Li2FePO4F as cathode in Li-ion batteries, Biointerface Research in Applied chemistry, Volume 9, Issue 2, 3866 - 3873, https://doi.org/10.33263/BRIAC92.866873

Pham, T.T., Monajjemi, M., Dang, D.M.T., Mollaamin, F., Dang, C.M., (2019), Reaction of cell membrane bilayers "as a variable capacitor" with G-protein: a reason for neurotransmitter signaling, Biointerface Research in Applied chemistry, Volume 9, Issue 2, 2019, 3874 - 3883, https://doi.org/10.33263/BRIAC92.874883

Pham, T.T., Monajjemi, M., Dang, D.M.T., Mollaamin, F., Dang, C.M., (2019) Nano-capacitors as batteries including graphene electrodes and Ga-N mixed with biopolymers as insulator, Biointerface Research in Applied chemistry, Volume 9, Issue 1, 2019, 3806 - 3811, https://doi.org/10.33263/BRIAC91.806811

Price DK, Ball JR, Bahrani-Mostafavi Z, Vachris JC, Kaufman JS, Naumann RW, Higgins RV, Hall JB: (2000), The phosphoprotein Op18/stathmin is differentially expressed in ovarian cancer. Cancer Invest 18:722-730. 
Ringhoff, D and Cassimeris, L., (2009) Stathmin regulates centrosomal nucleation of microtubules and tubulin dimer/polymer partitioning. Mol. Biol Cell. 20, 3451-3458. https://doi.org/10.1091/mbc.E09-020140 PMID: 19515833

Rusan, N.M., Tulu, U.S., Fagerstrom, C and Wadsworth, P., (2002) Reorganization of the microtubule array in prophase/prometaphase requires cytoplasmic dynein-dependent microtubule transport. J Cell Biol.,158: 997-1003. https://doi.org/10.1083/jcb.200204109 PMID: 12235119

Ravelli, R. B. G., Gigant, B., Curmi, P. A., Jourdain, I., Lachkar, S., Sobel, A., and Knossow, M. (2004). Insight into tubulin regulation from a complex with colchicine and a stathmin-like domain. Nature 428, 198-202.

Rowlands DC, Williams A, Jones NA, Guest SS, Reynolds GM, Barber PC, Brown G: Stathmin expression is a feature of proliferating cells of most, if not all, cell lineages. Lab Invest 1995, 72:100-113.

Sahu et al. (2013) Atomic water channel controlling remarkable properties of a single brain microtubule: Correlatig single protein to its supramolecular assembly. Biosens. Bioelectron. 47, 141-148.

Wade, R. H., Chrétien, D., and Job, D. (1990). Characterization of microtubule protofilament numbers. How does the surface lattice accommodate? J. Mol. Biol. 212, 775-786

Vale, R. D. (2003). The molecular motor toolbox for intracellular transport. Cell 112, 467-480

Zakharov, P., N. Gudimchuk, V. Voevodin, A. Tikhonravov, F.I. Ataullakhanov, and E.L. Grishchuk. (2015) Molecular and Mechanical Causes of Microtubule Catastrophe and Aging. Biophys. J. 109:25742591. https://doi.org/ 10.1016/j.bpj.2015.10.048 